\title{
Hyaluronic acid accelerates bone repair in human dental sockets: a randomized triple-blind clinical trial
}

\section{Carlos Eduardo Pinto ALCÂNTARA ${ }^{(a)}$ Maurício Augusto Aquino CASTRO(a) Mariana Saturnino de NORONHA ${ }^{(b)}$ Paulo Antônio MARTINS-JUNIOR ${ }^{(c)}$ Renato de Melo MENDES(d) Marcelo Vidigal CALIARI(e) Ricardo Alves MESQUITA(b) Anderson José FERREIRA ${ }^{(\mathrm{d})}$}

(a) Universidade Federal de Juiz de Fora UFJF, Life Sciences Institute, Department of Dentistry, Governador Valadares, MG, Brazil.

(b) Universidade Federal de Minas Gerais, School of Dentistry, Department of Oral Surgery and Pathology, Belo Horizonte, MG, Brazil.

(c) Universidade Federal de Minas Gerais, School of Dentistry, Department of Pediatric Dentistry and Orthodontics, Belo Horizonte, MG, Brazil.

(d) Universidade Federal de Minas Gerais, Biological Sciences Institute, Department of Morphology, Belo Horizonte, MG, Brazil.

(e) Universidade Federal de Minas Gerais, Biological Sciences Institute, Department of General Pathology, Belo Horizonte, MG, Brazil.

Declaration of Interest: The authors certify that they have no commercial or associative interest that represents a conflict of interest in connection with the manuscript.

\section{Corresponding Author:}

Anderson José Ferreira, DDs, PhD

E-mail: andersonicb@gmail.com

https://doi.org/10.1590/1807-3107bor-2018.vol32.0084

Submitted: March 02, 2018

Accepted for publication: June 26, 2018

Last revision: July 16, 2018
Abstract: This study evaluated the effects of hyaluronic acid (HA) on bone repair of human dental sockets. Thirty-two lower first premolars were extracted from 16 patients ( 2 per patient) for orthodontic reasons. Following the extractions, one socket was randomly filled with $1 \%$ HA gel, while the other was allowed to naturally fill with blood clot. After 30 and 90 days of surgery, patients underwent cone beam computed tomography. Five central orthoradial slices were captured from each socket. The gray intensity was measured in each image and results were reported as mean percentage of bone formation. The buccolingual alveolar ridge width was measured and dimensional changes were compared between the postoperative intervals. The pattern of alveolar trabecular bone was evaluated through the fractal dimension. Treated sockets showed a higher percentage of bone formation and fractal dimension values (58.17\% and 1.098, respectively) compared with controls (48.97\% and 1.074, respectively) in the 30-day postoperative period ( $p<0.05)$. After 90 days, there was no significant difference between groups. Additionally, no significant difference was found between groups regarding the alveolar dimensions ( $p>0.05)$. Use of $1 \%$ HA gel after tooth extraction accelerates bone repair in human dental sockets.

Keywords: Hyaluronic Acid; Tooth Socket; Cone-Beam Computed Tomography.

\section{Introduction}

Tooth extraction due to dental caries, periodontal disease, musculoskeletal diseases, and facial trauma can lead to a progressive and irreversible bone loss. As one of the main therapeutic problems in the dental clinic, ${ }^{1}$ bone loss has a great impact on dental support, esthetics, phonetics, masticatory capacity, osseointegration, and denture stability. ${ }^{2}$ In such cases, bone surgeries and/or biomaterials grafting can be necessary for the adequate oral rehabilitation of patients. ${ }^{1}$

Hyaluronic acid (HA), also known as sodium hyaluronate (HY) or hyaluronan (HYA), is a high molecular weight glycosaminoglycan (GAG) composed of repeating disaccharide non-sulfated units of D-glucuronic acid and $\mathrm{N}$-acetylglucosamine. ${ }^{3} \mathrm{HA}$ is a biomolecule of considerable importance since it is one of the major components of the extracellular matrix and widely distributed in several tissues, such as skin, synovial fluid, cartilage, tendons, eyes, and most body fluids. ${ }^{4,5}$ 
Due to its participation in several biological processes related to morphogenesis and tissue healing along with its biocompatibility, biodegradability, and nonimmunogenicity, HA, in the last decades, has become widely studied as a powerful biomaterial for tissue engineering. ${ }^{6,7} \mathrm{It}$ plays a key role during bone repair by stimulating cell migration, adhesion, and proliferation of undifferentiated mesenchymal cells inducing their differentiation into osteoblastic cells. . $^{8,9,10}$ Because of its physicochemical properties, it can retain osteoinductive growth factors into the local environment, as well as mediate the adhesion of osteoclasts to the bone surface and accelerate revascularization and bone formation in vitro. ${ }^{4,11,12}$

More recently, HA-based materials have been applied into bone defects of animal models alone, associated to scaffolds, or as a carrier of growth factors, promoting and/or enhancing bone formation. ${ }^{13,14}$ Accordingly, Mendes et al. ${ }^{13}$ reported that $1 \%$ HA accelerates the healing process after extraction of maxillary first molars of rats by stimulating the expression of osteogenic proteins, such as BMP-2 and osteopontin.

Despite the fact that HA is widely used in many medical fields, such as dermatology as a dermal filler, ${ }^{15}$ ophthalmology, ${ }^{16}$ and orthopedics as an anti-inflammatory agent in various inflammatory conditions, clinical applications of HA in Dentistry are still little known. Recent investigations found that HA appears to offer a beneficial effect on the management of swelling and trismus ${ }^{17}$ and on the inflammatory reaction following third molar extraction surgery..$^{18}$ Also, along with guided tissue regeneration, a HA-based matrix induced a significant added benefit in terms of clinical attachment level (CAL) gain, reduction of radiographic defect depth, and probing pocket depth. ${ }^{19}$ In addition, significantly improved outcomes following esthetic reconstruction of interdental papilla loss were observed. ${ }^{20}$ Regarding wound healing, the use of a gel containing amino acids and HY promoted faster healing by secondary intention in laser-induced wounds. ${ }^{21}$ Thus, the effects of HA on human bone repair in maxillofacial regions remain to be investigated, mainly in terms of bone repair. In this context, the aim of the present study was to evaluate the effects of HA on bone repair of human dental sockets.

\section{Methodology}

\section{Study design}

This study was approved by the National Research Ethics Committee (CONEP) (protocol \#656/2011), registered in the clinicaltrials.gov platform (\#NCT02709525) and conducted in accordance with the Consolidated Standards of Reporting Trials (CONSORT) statement. ${ }^{22}$ It wa a prospective, randomized, controlled (split-mouth), and triple-blind clinical trial. Each patient signed a statement of informed consent prior to participation in the study. For patients under 18 years old, their parents/caregivers signed the statement of informed consent.

There was no change in the methodology after the trial commencement.

\section{Sample size calculation and pilot study}

The sample size was calculated based on the outcome measure percentage of bone formation and the estimate for the comparison of repeated quantitative measurements was used for calculation. ${ }^{23}$ A 95\% confidence level, a standard deviation of 207.327, and a difference between groups of at least 5 points (parameters obtained from a pilot study involving 5 patients) were considered to calculate the sample size. A minimum of 16 patients was determined.

\section{Sample selection and eligibility criteria}

The subjects were carefully selected from the orthodontic clinics of the Brazilian Dental Association (ABO-MG), as well as of the Federal University of Minas Gerais (UFMG) from August 2012 to July 2015, and the surgeries and follow-ups ended in March 2016. All patients responded to a health questionnaire and were clinically evaluated. The inclusion criteria were healthy volunteers aged 14 to 40 years with an orthodontic indication for bilateral extraction of mandibular first premolars. The exclusion criteria were history of alcoholism, smoking and/or drug abuse; pregnancy or lactation; systemic diseases (uncontrolled diabetes, blood dyscrasias, kidney or heart failure, and osteoporosis); clinical or radiographic signs of 
bone pathological processes, premolars with dental caries, periodontal disease, endodontic treatment or root fracture; and hypersensitivity to the drugs or other substances employed in the study.

\section{Randomization}

Each patient underwent bilateral extraction of the lower first premolars, and the sockets were randomly divided into: i) sockets filled with $1 \%$ HA (group A) and ii) sockets filled with blood clot - control (group B). A researcher who was not directly involved in the outcomes evaluation performed the randomization using two opaque, labeled, and sealed envelopes. The envelope \#1 contained 16 cards labeled right or left and the envelope \#2 contained 16 cards labeled with the groups (group A or group B). A sequentially numbered list (1 to 16 - the number of patients) with a combination obtained by means of a draw of the group and side of the surgery was created. After determining the side that should be filled with HA, the contralateral side was automatically designated as control. The specific combination (HA-left and controlright, for example) of the 16 cases was known only by the researcher responsible for randomization. For each patient enrolled, this researcher informed the assistant surgeon which side was allocated to receive HA.

\section{Surgical procedures and dental sockets treatment}

A single operator performed the extraction procedures. The HA gel (NIKKOL manufacturer) was provided by BS Pharma, Belo Horizonte, MG, Brazil. Application of the HA gel was made by the assistant surgeon. The extractions of both lower premolars were performed under local anesthesia [2\% lidocaine with 1:100,000 epinephrine (Alphacaine 100; DFL, Rio de Janeiro, RJ, Brazil)], and a forceps for premolars (\#151) (Quinelato, Rio Claro, SP, Brazil) was used following the standard technique. The sockets were sutured with interrupted " $X$ " stitches using 5.0 silk thread (Technew, Rio de Janeiro, RJ, Brazil). Immediately after the sutures, the selected socket was filled with $1 \%$ HA (approximately $1 \mathrm{~mL}$ ) using a sterile disposable syringe and needle (Descarpack, São Paulo, SP, Brazil), while the contralateral socket was left untreated, naturally filled with blood clot.
The syringe was taken into position for 30 seconds in both sockets, but the HA gel was applied only in the socket selected to receive the treatment. This maneuver was aimed at keeping the patient unaware of which socket received the treatment.

All patients received the same post-surgical medication [paracetamol/acetaminophen $750 \mathrm{mg}$ (Janssen Cilag Farmacêutica, São Paulo, SP, Brazil) every 6 hours, as needed for pain control, for a maximum of 3 days] and post-operative written recommendations. Patients were not informed about which side received HA. At the end of the surgical procedure, patients were instructed to maintain a sterile gauze between the arches for approximately 30 minutes.

\section{Cone beam computed tomography (CBCT)}

Each patient underwent CBCT scans at two postoperative periods: 30 days and 90 days after surgery. The scans were performed in the I-CAT ${ }^{\circledast}$ device (Model Next Generation - Imaging Sciences International Hatfield, PA, USA). The examinations were performed with voxel of $0.25 \mathrm{~mm}, 7 \times 16 \mathrm{~cm}$ field of view, and exposure time of 26.9 seconds. The images obtained were used for analyzing the alveolar dimensional changes, morphometric evaluation of the percentage of newly formed bone, and mean fractal dimension (FD). These parameters were analyzed by a single trained and calibrated examiner who was blinded to which sockets received HA. This examiner went through a training exercise and calibration prior to the main study. Calibration was performed using random 10 images, in which the examiner performed the measurements in two separate occasions with a 15-day interval. The intra-class correlation coefficient ranged from 0.87 to 0.94 , showing that the examiner was calibrated for the analyses.

\section{Alveolar dimensional changes}

The images were evaluated as follows: a. the long axis of the socket was aligned vertically in the coronal and sagittal planes (during multiplane reconstruction); b. after the panoramic reconstruction, orthoradial slices ( $1 \mathrm{~mm}$ thick and $1 \mathrm{~mm}$ spacing) perpendicular to surfaces of buccolingual plates of the alveolar ridge on axial view were determined in the region 
where the tooth was extracted; c. in the 30-day period, the distance from the apex to the outer limit of the basilar in the most central slice (standardization for evaluation of the 90-day tomography) was measured; d. subsequently, the socket was measured (apex to cervical) and divided into three thirds (cervical, middle, and apical). The buccolingual alveolar ridge width was measured and compared with the postoperative data to evaluate possible alveolar dimensional changes. The measurements were made at the center of each third portion of the socket: cervical, middle, and apical.

\section{Morphometric evaluation and fractal dimension analysis}

The methodology used to measure bone formation inside the tooth sockets was adapted from Miranda et al. ${ }^{24}$ Five representative images of each socket were captured, totaling 80 images per group. In each image, the examiner delimited the area of the socket (region of interest - ROI) and the gray intensity was measured using the KS300 software coupled to a Carl Zeiss image analyzer (Carl Zeiss, Oberkochen, Germany). The high intensity areas (HIA) corresponded to the more mature bone tissue, while the weak intensity areas (WIA) corresponded to fibrin matrix, inflammatory process, and blood clot. Thus, at the delimited dental socket area (ROI), pixels of light gray tones corresponding to areas of bone formation were selected and then a binary image was created to calculate the area in $\mathrm{mm}^{2}$. Then, all pixels of the ROI were selected for the calculation of the socket total area (STA). The percentage of formed bone was obtained through the following formula: mean socket filling $=\left[\mathrm{HIA}\left(\mathrm{mm}^{2}\right) / \mathrm{STA}\left(\mathrm{mm}^{2}\right)\right] \times 100$.

To perform fractal dimension (FD) analysis, five digital images of each side were processed in accordance to White and Rudolph. ${ }^{25}$ Data were analyzed with the ImageJ software (Image J, US National Institutes of Health, Bethesda, MD, USA). The ROI analysis was defined as encompassing all socket extension, excluding the alveolar lamina dura. The calculation of the FD was conducted by the box-counting method. The ROI was selected, cropped, and subsequently duplicated. This double image was blurred with a Gaussian filter (sigma-35) and subtracted from the original image. Then, a gray value of 128 was added to each pixel location and the resultant image was converted into a binary image, with black representing bone and white representing marrow spaces. The image was eroded and dilated to reduce noise and finally skeletonized for FD analysis (Figure 1).

\section{Statistical analysis}

Data were organized in the Statistical Package for Social Sciences (SPSS) version 20.0 Statistics (IBM Corp., Armonk, NY, USA). Descriptive statistics were performed, as well as the Shapiro-Wilk normality test to evaluate the distribution of the data. Non-parametric (Wilcoxon) or parametric (paired Student's $t$ test) tests were used to compare the groups. The level of significance for all the analyzed data was $p<0.05$. The statistician was also unaware treatment, which was only revealed after the data acquisition and analysis.

\section{Results}

Flow diagram for patient recruitment and selection is displayed in Figure 2. Thirty-two lower premolars were extracted from 16 patients with a mean age of 18.67 (SD = 7.95) years with orthodontic indication of bilateral extraction. Patients participated of all stages of the trial and there was no segment loss. The sockets filled with $1 \%$ HA presented a higher percentage of newly formed bone than the untreated sockets in the postoperative period of 30 days $(p=0.004)$ (Figures 3 and 4). However, no significant difference was observed in the 90 -day period ( $p=0.216$ ) (Figure 3 ).

In terms of buccolingual alveolar ridge width at the three thirds of the sockets, no significant difference was viewed between the groups ( $p>0.05)$ (Table). Also, when comparing the evolution of bone loss between the first and third postoperative month, no significant difference between the groups was found. The mean bone losses in the cervical, middle, and apical thirds were $0.71,0.25$, and 0.19 for HA-treated sockets and $0.75,0.54$, and 0.21 for the control sockets. Regarding the analysis of the FD, a significant increase in the HA-treated group at 30 days $(1.098 \pm 0.042 \mathrm{vs}$. $1.074 \pm 0.045$ in control group, $p=0.003$ ) was found, but not at 90 days after the surgery, when compared with the untreated group (Figure 5). 

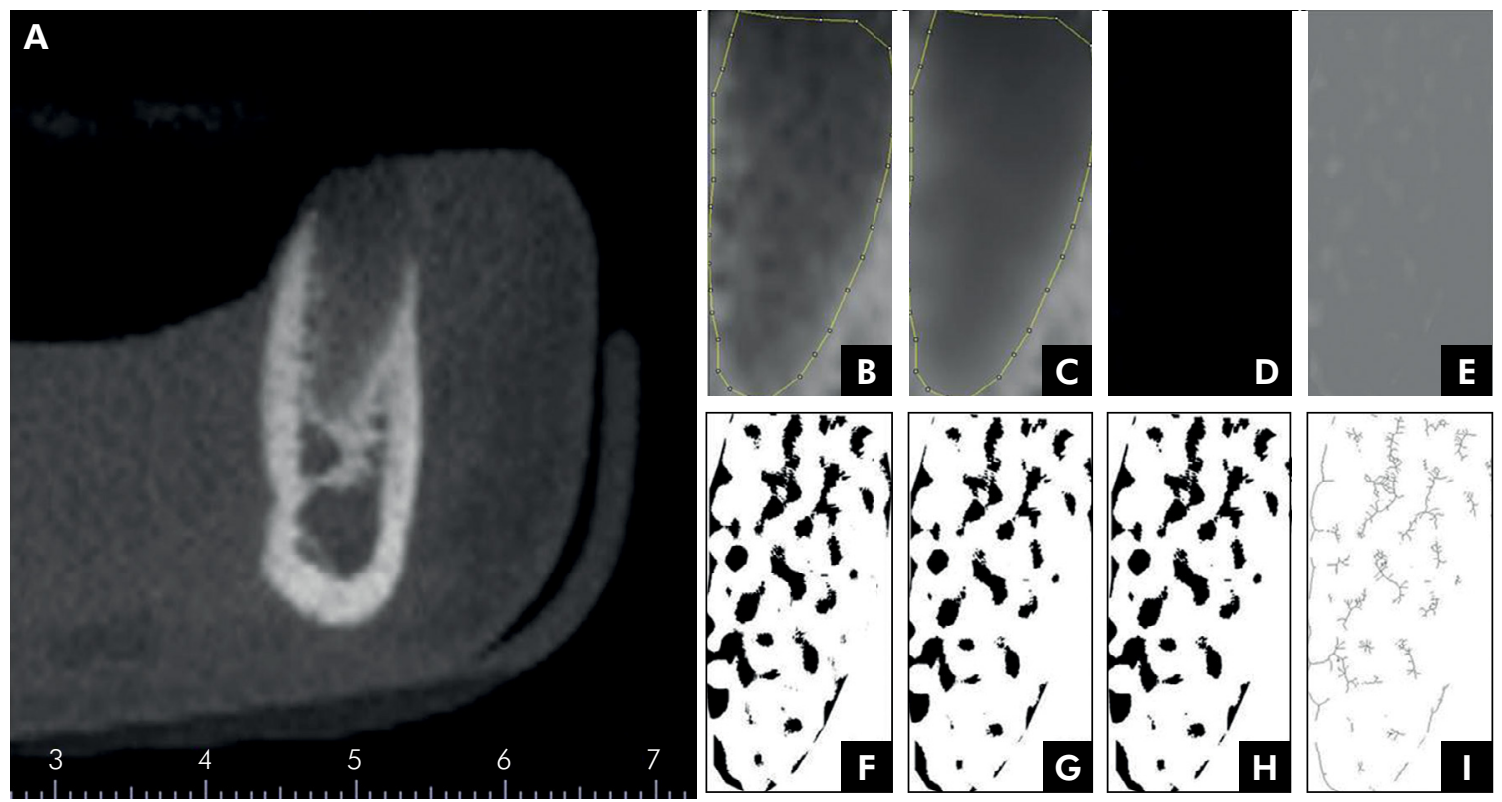

Figure 1. Steps for fractal dimension analysis of dental socket. A - orthoradial slice of cone beam computed tomography; B selected region of interest (socket); C - blurred image with Gaussian filter; D - image subtraction result; $\mathrm{E}$ - added gray value of 128; F - binary image; $\mathrm{G}$ - eroded image; $\mathrm{H}$ - dilated image; I - skeletonized image.

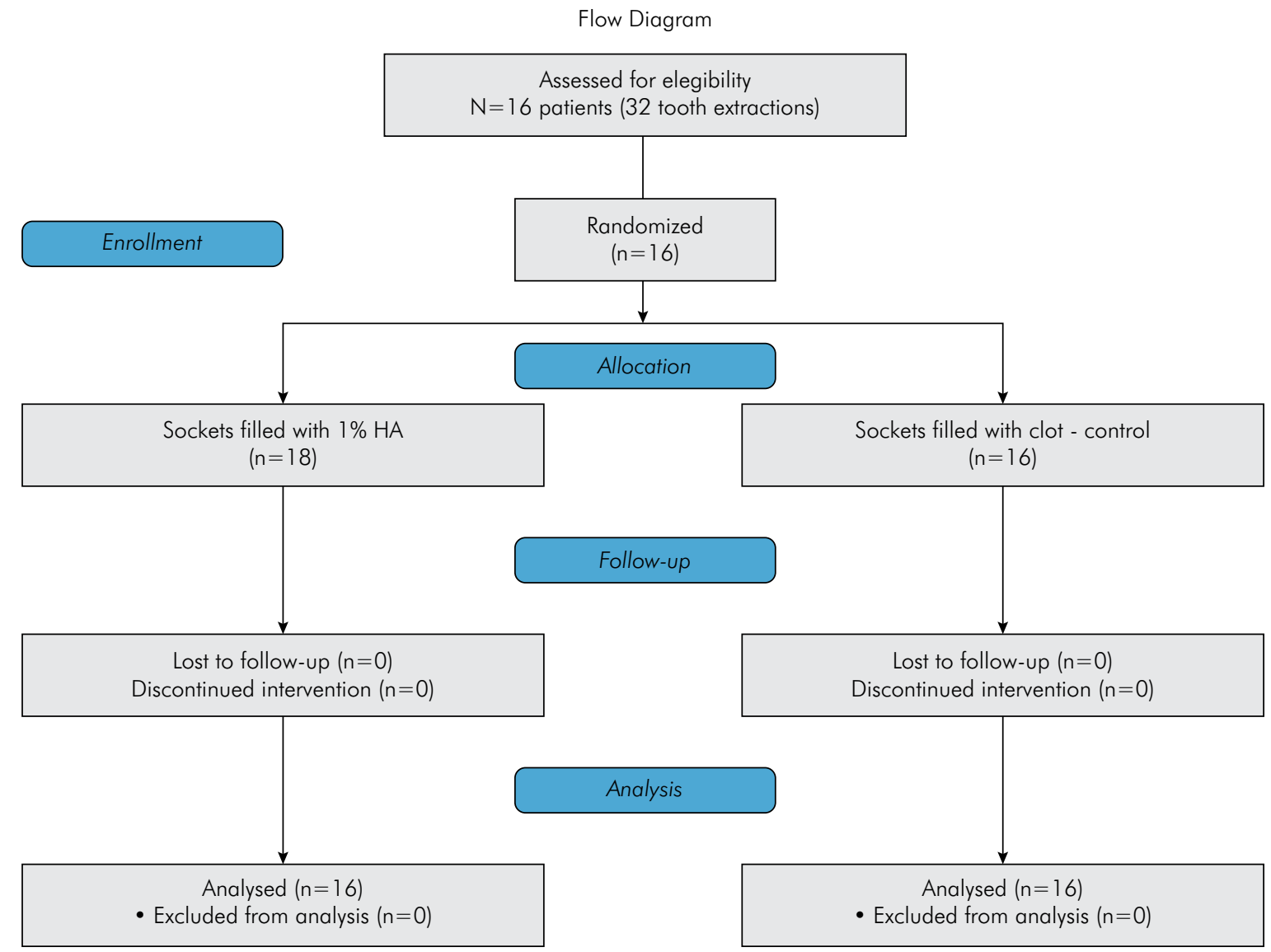

Figure 2. Study flow diagram. 


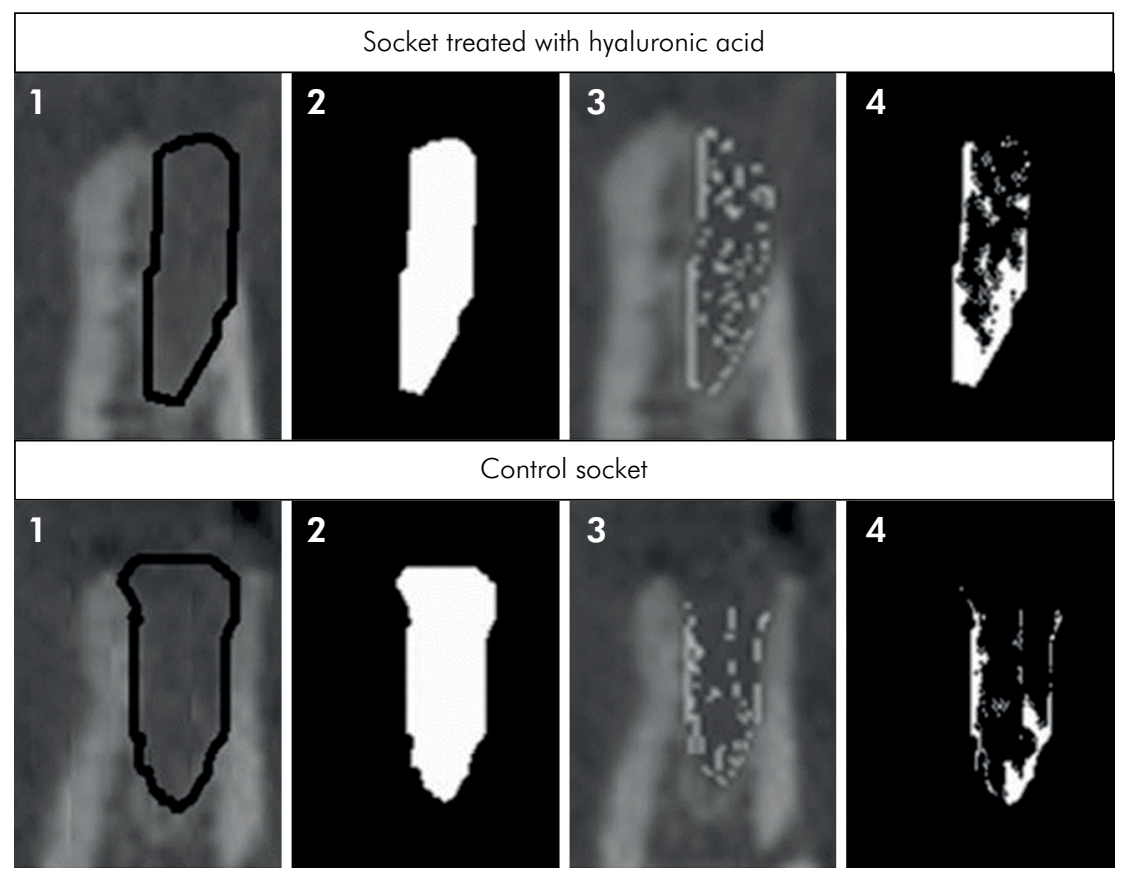

Figure 3. Representative slices of cone beam computed tomography of control and $1 \%$ hyaluronic acid (HA)-treated sockets at 30 days after tooth extraction. Top panel - socket treated with HA; bottom panel - control socket. 1 - delimitation of the region of interest (dental socket); 2 - total area of the socket; 3 - overlapped area of intra-alveolar newly formed bone; 4 - demarcation of high intensity areas.

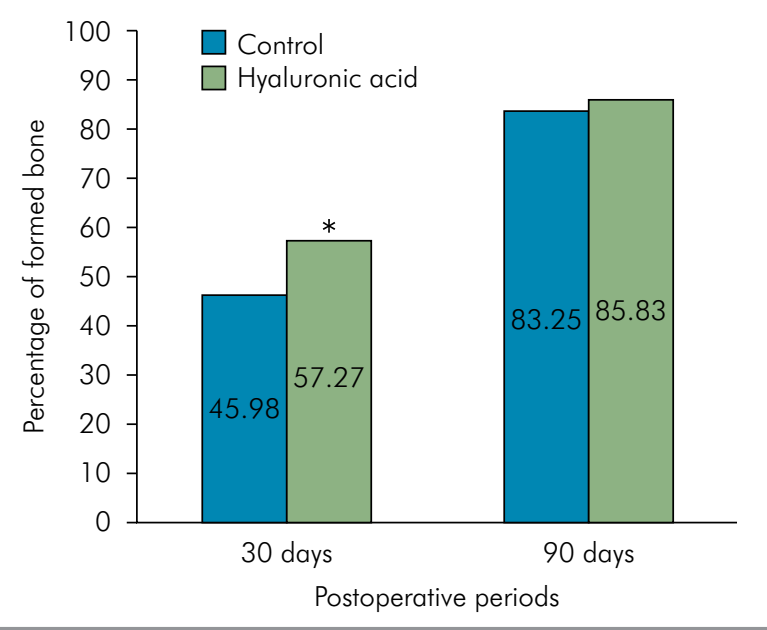

Figure 4. Percentage of newly formed bone in tooth sockets of hyaluronic acid $(\mathrm{HA})$ and control groups at 30 and 90 days after surgery. ${ }^{*} p<0.05$ (Paired t test).

\section{Discussion}

The purpose of this study was to investigate if sockets filled with HA gel present any improvement on bone formation regarding time and alveolar dimension preservation. To the best of our knowledge, this is the first study to assess the effect of HA on bone formation
Table. Buccolingual alveolar ridge width at the three thirds of the sockets (cervical, middle, and apical).

\begin{tabular}{lcccc}
\hline \multirow{2}{*}{$\begin{array}{l}\text { Postoperative } \\
\text { interval }\end{array}$} & $\begin{array}{c}\text { Socket } \\
\text { third }\end{array}$ & \multicolumn{2}{c}{$\begin{array}{c}\text { Experimental group - } \\
\text { mean (SD) }\end{array}$} & p-value \\
\cline { 3 - 4 } & & Control & HA & \\
\hline 30 days & Cervical & $7.90(1.34)$ & $8.29(1.43)$ & \\
& Middle & $8.87(1.72)$ & $8.83(1.71)$ & $>0.05$ \\
& Apical & $9.31(1.75)$ & $9.23(1.88)$ & \\
90 days & Cervical & $7.14(1.26)$ & $7.73(1.40)$ & \\
& Middle & $8.33(1.68)$ & $8.57(1.89)$ & $>0.05$ \\
& Apical & $9.09(1.68)$ & $9.04(2.06)$ & \\
\hline
\end{tabular}

No significant differences between the groups were found. Paired T-test or Wilcoxon Test.

in human dental sockets. In tooth sockets of rats, HA accelerated the healing process after extraction of first molars. ${ }^{13}$ Histological and morphometric analyses showed a significant increase in bone trabeculae at 7 and 21 days after tooth extraction and number of blood vessels at 7 days. Furthermore, the expression of BMP-2 and osteopontin were enhanced in HA-treated sockets. ${ }^{13}$ 
A

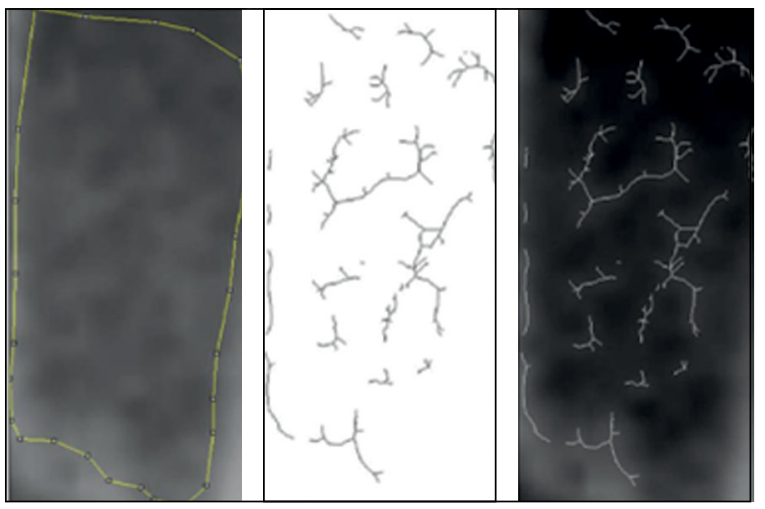

B

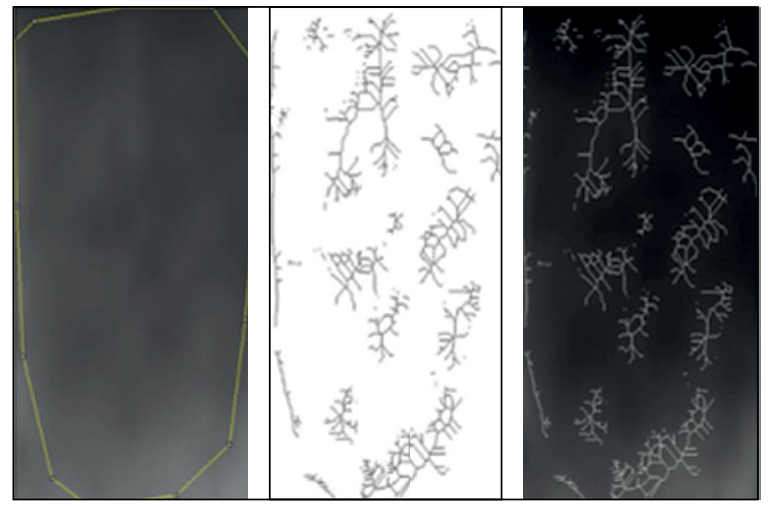

Figure 5. Representative (1) original image, (2) skeletonized image, and (3) overlapped images of (A) control socket and (B) hyaluronic acid (HA)-treated socket after 30 days of healing process.

The experimental model adopted (split-mouth) enables each patient to act as his/her own control, minimizing individual factors that might interfere in the results of the study. The use of fresh sockets of lower first premolars with orthodontic extraction indication was practical, since these teeth have only one root, have no signs of inflammation, and are frequently extracted due to orthodontic treatment. On the other hand, the impossibility of performing histological analysis and long-term evaluation represent important limitations of the study model.

Many strategies adopted immediately after extraction have proven to maintain bone dimensions. ${ }^{26}$ The process of resorption and bone remodeling is more intense in the first three months after extraction and the control of this process remains a challenge in Dentistry. At 30 days, it was observed that bone formation was more advanced in sockets filled with HA, whereas at 90 days treated and control sockets had similar bone density pattern, showing that the biomaterial had a positive influence in the beginning of the alveolar healing process. In this context, authors have shown that HA plays a crucial role in wound healing and inflammatory processes since it can bind to several important proteins of the healing cascade such as fibrin, fibrinogen, fibronectin, and collagen. ${ }^{3,27}$ In addition, it has been proposed that HA can protect the granulation tissue from damage caused by oxygen free radicals by its ability to eliminate reactive oxygen species. ${ }^{28}$ The HA molecule probably interacts with CD44 or RHAMM on the surface of endothelial cells, although the contribution of each receptor is controversial. ${ }^{29}$

Evaluation of bone formation using CBCT is done using various methods without standardization, making it difficult to compare studies. The use of Hounsfield units (HU) is a controversial subject in the literature since the consistency and accuracy of the values remain elusive. ${ }^{26}$ On the other hand, a study ${ }^{24}$ carried out morphometric analysis using the software KS300, applying the gray intensity to compare bone formation in images captured by CBCT.

Because trabecular bone structure is quite complex, numerical quantification of bone formation is also complex. Trabecular bone has a branching pattern that displays fractal properties, such as statistical self-similarity and lack of well-defined scale. Thus, due to these phenomena, the application and analysis of fractal geometry can be used to determine the complexity and trabecular bone structure. ${ }^{30} \mathrm{FD}$, a numerical expression of the fractal analysis, is a method of analysis relatively new in Dentistry. It can be calculated by different ways, but the most common method in dental $\mathrm{x}$-rays and CT scans is the box counting due to its easy implementation and access. ${ }^{31}$ In general, FD has a good correlation with bone mass ${ }^{32}$ and it has been used as a tool to detect early changes in periapical trabecular bone pattern after endodontic treatment. ${ }^{33,34}$ In addition, FD associated with CBCT has been utilized to evaluate bone alterations in patients with osteonecrosis linked to bisphosphonates, ${ }^{35}$ as well as bone formation in 
studies of dental implants. ${ }^{36,37}$ In our study, it was possible to evaluate the bone structural complexity and observe that the sockets that received HA had a higher bone formation. Unfortunately, due to methodological differences among the studies, these results cannot be compared with other works.

For these reasons, various strategies that involve alveolar ridge preservation and/or replacement of the bone structure have been proposed to overcome atrophic changes in the alveolar process healing. ${ }^{38}$ Here, no difference in relation to dimensional changes of the alveolar process was observed. A similar result was found in a previous study comparing dimensional changes between sockets filled with an osteoinductive allograft and with blood clot. ${ }^{39}$ On the other hand, the capacity of HA to accelerate bone repair during the first 30 days after surgery can lead to an improved patient well-being, since it appears to reduce postoperatory signals/symptoms such as trismus and swelling. ${ }^{17}$ Besides that, some studies have shown that HA possesses antibacterial properties ${ }^{40}$ which is a desirable action during surgical interventions.

Although in the last few years the antiinflammatory, osteoinductive, bacteriostatic, and other beneficial effects of HA have emerged as possible therapies in Dentistry, its full effectiveness for clinical application still requires further investigations. The results of the current study are promising from the viewpoint of bone formation. It is noteworthy that it was not possible to perform histological analysis, as the methodology did not allow bone biopsy. Also, the lack of an initial CBCT (after tooth extraction), which would be helpful to better understand the healing process, represents a limitation of the study.

Future clinical studies in humans involving both radiographic diagnosis of bone formation and histological evaluation can bring a new perspective on how to accelerate alveolar bone formation using $\mathrm{HA}$. The use of HA in less than ideal situations, such as in teeth with periapical lesions would also be worth studying to evaluate the behavior of the healing process. Furthermore, the use of HA in association with other materials can be an excellent strategy in oral regenerative medicine.

\section{Acknowledgments}

The work was supported by the Coordenação de Aperfeiçoamento de Pessoal de Nível Superior (Capes - Brazil), Fundação de Amparo à Pesquisa do Estado de Minas Gerais (Fapemig - Brazil) and Conselho Nacional de Desenvolvimento Científico e Tecnológico (CNPq - Brazil). Providers of funding had no role in the study design, data collection and analysis, publishing decisions or preparation of the manuscript.

\section{References}

1. Bodic F, Hamel L, Lerouxel E, Baslé MF, Chappard D. Bone loss and teeth. Joint Bone Spine. 2005 May;72(3):215-21. https://doi.org/10.1016/i.jbspin.2004.03.007

2. Pang C, Ding Y, Zhou H, Qin R, Hou R, Zhang G et al. Alveolar ridge preservation with deproteinized bovine bone graft and collagen membrane and delayed implants. J Craniofac Surg. 2014 Sep;25(5):1698-702. https://doi.org/10.1097/SCS.0000000000000887

3. Aslan M, Simsek G, Dayi E. The effect of hyaluronic acidsupplemented bone graft in bone healing: experimental study in rabbits. J Biomater Appl. 2006 Jan;20(3):209-20. https://doi.org/10.1177/0885328206051047

4. Prince $\mathrm{CW}$. Roles of hyaluronan in bone resorption. BMC Musculoskelet Disord. 2004 Apr;5(1):12. https://doi.org/10.1186/1471-2474-5-12

5. Falcone SJ, Palmeri DM, Berg RA. Rheological and cohesive properties of hyaluronic acid. J Biomed Mater Res A. 2006 Mar;76(4):721-8. https://doi.org/10.1002/jbm.a.30623PMID:16315193

6. Zhao N, Wang X, Qin L, Zhai M, Yuan J, Chen J et al. Effect of hyaluronic acid in bone formation and its applications in dentistry. J Biomed Mater Res A. 2016 Jun;104(6):1560-9. https://doi.org/10.1002/jbm.a.35681

7. Chen F, Ni Y, Liu B, Zhou T, Yu C, Su Y et al. Self-crosslinking and injectable hyaluronic acid/RGD-functionalized pectin hydrogel for cartilage tissue engineering. Carbohydr Polym. 2017 Jun;166:31-44. https://doi.org/10.1016/i.carbpol.2017.02.059

8. Dechert TA, Ducale AE, Ward SI, Yager DR. Hyaluronan in human acute and chronic dermal wounds. Wound Repair Regen. 2006 May-Jun;14(3):252-8. https://doi.org/10.1111/j.1743-6109.2006.00119.x 
9. Kim J, Kim IS, Cho TH, Lee KB, Hwang SJ, Tae G et al. Bone regeneration using hyaluronic acid-based hydrogel with bone morphogenic protein-2 and human mesenchymal stem cells. Biomaterials. 2007 Apr;28(10):1830-7. https://doi.org/10.1016/i.biomaterials.2006.11.050

10. Pasquinelli G, Orrico C, Foroni L, Bonafè F, Carboni $M$, Guarnieri $C$ et al. Mesenchymal stem cell interaction with a non-woven hyaluronan-based scaffold suitable for tissue repair. J Anat. 2008 Nov;213(5):520-30. https://doi.org/10.1111/j.1469-7580.2008.00974.x

11. Sasaki T, Watanabe C. Stimulation of osteoinduction in bone wound healing by high-molecular hyaluronic acid. Bone. 1995 Jan;16(1):9-15. https://doi.org/10.1016/8756-3282(95)80005-B

12. Giavaresi G, Torricelli P, Fornasari PM, Giardino R, Barbucci R, Leone $G$. Blood vessel formation after soft-tissue implantation of hyaluronan-based hydrogel supplemented with copper ions. Biomaterials. 2005 Jun;26(16):3001-8. https://doi.org/10.1016/i.biomaterials.2004.08.027

13. Mendes RM, Silva GA, Lima MF, Calliari MV, Almeida AP, Alves $\mathrm{JB}$ et al. Sodium hyaluronate accelerates the healing process in tooth sockets of rats. Arch Oral Biol. 2008 Dec;53(12):115562. https://doi.org/10.1016/i.archoralbio.2008.07.001

14. Suzuki K, Anada T, Miyazaki T, Miyatake N, Honda Y, Kishimoto $\mathrm{KN}$ et al. Effect of addition of hyaluronic acids on the osteoconductivity and biodegradability of synthetic octacalcium phosphate. Acta Biomater. 2014 Jan;10(1):531-43. https://doi.org/10.1016/j.actbio.2013.09.005

15. Hemshekhar M, Thushara RM, Chandranayaka S, Sherman LS, Kemparaju K, Girish KS. Emerging roles of hyaluronic acid bioscaffolds in tissue engineering and regenerative medicine. Int J Biol Macromol. 2016 May;86:917-28. https://doi.org/10.1016/j.ijbiomac.2016.02.032

16. Kretz FT, Limberger IJ, Auffarth GU. Corneal endothelial cell coating during phacoemulsification using a new dispersive hyaluronic acid ophthalmic viscosurgical device. J Cataract Refract Surg. 2014 Nov;40(11):1879-84. https://doi.org/10.1016/i.jcrs.2014.04.025

17. Koray M, Ofluoglu D, Onal EA, Ozgul M, Ersev H, Yaltirik M et al. Efficacy of hyaluronic acid spray on swelling, pain, and trismus after surgical extraction of impacted mandibular third molars. Int J Oral Maxillofac Surg. 2014 Nov;43(11):1399-403. https://doi.org/10.1016/i.ijom.2014.05.003

18. Gocmen G, Gonul O, Oktay NS, Yarat A, Goker K. The antioxidant and anti-inflammatory efficiency of hyaluronic acid after third molar extraction. J Craniomaxillofac Surg. 2015 Sep;43(7):1033-7. https://doi.org/10.1016/i.jcms.2015.04.022

19. Sehdev B, Bhongade ML, Ganji KK. Evaluation of effectiveness of hyaluronic acid in combination with bioresorbable membrane (poly lactic acid-poly glycolic acid) for the treatment of infrabony defects in humans: A clinical and radiographic study. J Indian Soc Periodontol. 2016 JanFeb;20(1):50-6. https://doi.org/10.4103/0972-124X.170809

20. Awartani FA, Tatakis DN. Interdental papilla loss: treatment by hyaluronic acid gel injection: a case series. Clin Oral Investig. 2016 Sep;20(7):1775-80. https://doi.org/10.1007/s00784-015-1677-z
21. Romeo U, Libotte F, Palaia G, Galanakis A, Gaimari G, Tenore $G$ et al. Oral soft tissue wound healing after laser surgery with or without a pool of amino acids and sodium hyaluronate: a randomized clinical study. Photomed Laser Surg. 2014 Jan;32(1):10-6. https://doi.org/10.1089/pho.2013.3509

22. Schulz KF, Altman DG, Moher D. CONSORT 2010 Statement: updated guidelines for reporting parallel group randomised trials. BMC Med. 2010 Mar;8(1):18. https://doi.org/10.1186/1741-7015-8-18

23. Jeke LJ, Katz DL, Elmore JG. Epidemiology, biostatistics, and preventive medicine. 2nd ed. Atlanta: Elsevier; 2001.

24. Miranda SC, Silva GA, Mendes RM, Abreu FA, Caliari MV, Alves JB et al. Mesenchymal stem cells associated with porous chitosan-gelatin scaffold: a potential strategy for alveolar bone regeneration. J Biomed Mater Res A. 2012 Oct;100(10):2775-86. https://doi.org/10.1002/jbm.a.34214

25. White SC, Rudolph DJ. Alterations of the trabecular pattern of the jaws in patients with osteoporosis. Oral Surg Oral Med Oral Pathol Oral Radiol Endod. 1999 Nov;88(5):628-35. https://doi.org/10.1016/S1079-2104(99)70097-1

26. Loveless TP, Kilinc Y, Altay MA, Flores-Hidalgo A, Baur DA, Quereshy FA. Hounsfield unit comparison of grafted versus non-grafted extraction sockets. J Oral Sci. 2015 Sep;57(3):195-200. https://doi.org/10.2334/josnusd.57.195

27. Stern M, Schmidt B, Dodson TB, Stern R, Kaban LB. Fetal cleft lip repair in rabbits: histology and role of hyaluronic acid. J Oral Maxillofac Surg. 1992 Mar;50(3):263-8. https://doi.org/10.1016/0278-2391(92)90323-R

28. Trabucchi E, Pallotta S, Morini M, Corsi F, Franceschini R, Casiraghi $A$ et al. Low molecular weight hyaluronic acid prevents oxygen free radical damage to granulation tissue during wound healing. Int J Tissue React. 2002;24(2):65-71.

29. Park D, Kim Y, Kim H, Kim K, Lee YS, Choe J et al. Hyaluronic acid promotes angiogenesis by inducing RHAMM-TGF $\beta$ receptor interaction via CD44-PKC $\delta$. Mol Cells. 2012 Jun;33(6):563-74. https://doi.org/10.1007/s10059-012-2294-1

30. Sanchez-Molina D, Velazquez-Ameiiide J, Quintana V, Arregui-Dalmases C, Crandall JR, Subit D et al. Fractal dimension and mechanical properties of human cortical bone. Med Eng Phys. 2013 May;35(5):576-82. https://doi.org/10.1016/i.medengphy.2012.06.024

31. Leite AF, Figueiredo PT, Caracas H, Sindeaux R. Guimarães AT, Lazarte L, Paula AP, Melo NS. Systematic review with hierarchical clustering analysis for the fractal dimension in assessment of skeletal bone mineral density using dental radiographs. Oral Radiol. 2015;31(1):1-13. https://doi.org/10.1007/s11282-014-0188-y.

32. Bollen AM, Taguchi A, Hujoel PP, Hollender LG. Fractal dimension on dental radiographs. Dentomaxillofac Radiol. 2001 Sep;30(5):270-5. https://doi.org/10.1038/si.dmfr.4600630

33. Chen SK, Oviir T, Lin CH, Leu LJ, Cho BH, Hollender L. Digital imaging analysis with mathematical morphology and fractal dimension for evaluation of periapical lesions following endodontic treatment. Oral Surg Oral Med Oral Pathol Oral Radiol Endod. 2005 Oct;100(4):467-72. https://doi.org/10.1016/..tripleo.2005.05.075 
Hyaluronic acid accelerates bone repair in human dental sockets: a randomized triple-blind clinical trial

34. Yu YY, Chen H, Lin CH, Chen CM, Oviir T, Chen SK et al. Fractal dimension analysis of periapical reactive bone in response to root canal treatment. Oral Surg Oral Med Oral Pathol Oral Radiol Endod. 2009 Feb;107(2):283-8. https://doi.org/10.1016/i.tripleo.2008.05.047

35. Torres SR, Chen CS, Leroux BG, Lee PP, Hollender LG, Schubert MM. Fractal dimension evaluation of cone beam computed tomography in patients with bisphosphonateassociated osteonecrosis. Dentomaxillofac Radiol. 2011 Dec;40(8):501-5. https://doi.org/10.1259/dmfr/14636637

36. González-Martín O, Lee EA, Veltri M. CBCT fractal dimension changes at the apex of immediate implants placed using undersized drilling. Clin Oral Implants Res. 2012 Aug;23(8):9547. https://doi.org/10.1111/j.1600-0501.2011.02246.x
37. Veltri $M$, Ferrari $M$, Balleri P. Correlation of radiographic fractal analysis with implant insertion torque in a rabbit trabecular bone model. Int J Oral Maxillofac Implants. 2011 Jan-Feb;26(1):108-14.

38. Jambhekar S, Kernen F, Bidra AS. Clinical and histologic outcomes of socket grafting after flapless tooth extraction: a systematic review of randomized controlled clinical trials. J Prosthet Dent. 2015 May;113(5):371-82. https://doi.org/10.1016/i.prosdent.2014.12.009

39. Brownfield LA, Weltman RL. Ridge preservation with or without an osteoinductive allograft: a clinical, radiographic, micro-computed tomography, and histologic study evaluating dimensional changes and new bone formation of the alveolar ridge. J Periodontol. 2012 May;83(5):581-9. https://doi.org/10.1902/jop.2011.110365

40. Rodrigues SV, Acharya AB, Bhadbhade S, Thakur SL. Hyaluronan-containing mouthwash as an adjunctive plaquecontrol agent. Oral Health Prev Dent. 2010;8(4):389-94. 